SOME REFLECTIONS ON THE TOURNAMENT RULES

FOR THE MICROCOMPUTER-CHESS CHAMPIONSHIP

\author{
J.J. van 0osterwijk Bruyn \\ President of the Netherlands \\ Computer-Chess Association (CSVN)
}

Drafting the rules for a computer-chess tournament entalls making a number of choices and anticipating their interpretation. We review here some of the alternatives considered while preparing the rules for the Fifth World Microcomputer-Chess Championship. We have tried to make rules that would be both enforceable and unambiguous. The participants will probably be quick to prove where we have failed. Not everyone will agree with our choices. Still, we hope that these considerations will contribute to better rules in future tournaments.

(a) Why propose two groups?

In Swiss-style events, major differences in playing strength as have been seen in previous Microcomputer tournaments vastly upset the tournament and its outcome. When having two groups, competitors' strength may be expected to be more homogeneous within groups. An additional advantage might be that "entry-level" programmers may be encouraged to participate when they are to meet second-group opponents nearer to their own programs' playing strength.

(b) How to distribute participants over the groups?

Ideally, distribution should be by playing strength only. This, however, raises a double problem. It would be difficult, though not perhaps impossible, for a Selection Committee to decide (on ELO ratings or earlier tournament results) which programs would be too weak to qualify for the main group. However, we may not exclude the possibility of a fairly strong program's author disguising his real strength so as to easily win in the second group! Therefore we have "closed the door" downward (from the main group to the second group) for commercial programs, but left open the "door upward" for amateur programs if they can justify their application for the main group by their playing strength. 
(c) Which types of computer to let particlpate?

We have followed last year's Glasgow decision to outlaw bit-slice machines: they should be considered to be disproportionately more powerful than those with a single (main) processor. Still, this leaves the range of qualifying computers pretty broad, including those "home-built" or "souped up" (say with an acceleration board). The processor might be a 16-b1t or even a 32-bit one, not even excluding computers with a main processor and a coprocessor (8086/8087) or having an auxillary processor $(8086 / 280)$.

Obviously, in the future we are going to see ever more powerful desk-top computers and drawing the line of eligibility is going to be more difficult. As of now, a "liberal" admission policy is to the advantage of the amateurs often developing their programs on such machines. ICCA should perhaps start a discussion about future requirements for computers and programs to participate in microcomputer-chess tournaments.

(d) Serious thought has been given on whether to allow a single manufacturer's programs to play one another. The point is nicely balanced: in a fair world, there would be a clear advantage in that each program would be judged on its merits. In the world as it is, side-effects might preponderate, it being only too easy to ' $f i x$ ' the outcome of a game within the same firm. Rumour has it that many firms would resort to 'fixing' if such should redound to their advantage. Perhaps the computers, like racing cars, should be put in a "parc fermé". Although there is no proof that competition would be seriously distorted by allowing the same firm's programs to compete, we have in the end decided against it. However, programs by one author but of different firms will be allowed to play one another.

(e) The definition of amateur programs (Rules for Participation, \# 2) implies that a programmer known to be working commerclally but never to have authored a commercial program must be considered an amateur. Hence, he will not be charged a fee and his participation may come additional to the three commercial entries any firm is allowed. 
To some, this consequence may seem undesirable. Yet, when a tournament would necessarily reveal a programmer to be affiliated to commerce, it might induce hypocracy by persuading workers to observe secrecy about their affiliations. The present rule, besides avoiding the hypocracy has the advantage of unequivocally assigning commercial or amateur status.

\title{
ANNOUNCEMENT
}

THE FIFTH WORLD COMPUTER-CHESS CHAMPIONSHIP

\author{
ICCA Communication \\ by D.N.L. Levy
}

The Fifth World Computer Chess Championship is now definitely known to be held in 1986 in Germany, at the invitation of the German Chess Federation. The ICCA has gratefully accepted the invitation; many details have already been settled by David Levy, the well-known international chess master. The venue is expected to coincide with the annual computer exhibition in Cologne, GFR, from June 13 th to $17 \mathrm{th}$, 1986, to within a day or two.

\section{RATING SUPER CONSTELLATION}

\author{
D.E. Welsh \\ Chatrman, US Chess Federation \\ Computer Chess Committee \\ Los Angeles
}

\begin{abstract}
A top-priority goal of the USCF's Computer Chess Committee for several years has been establishing a USCF Computer Rating Agency to provide reliable ratings for chess microcomputers and personal-computer chess programs.
\end{abstract}

\section{CREDIBILITY}

Ever since chess microcomputers first appeared in 1978, advertising claims have often overstated the computers' playing strength. Many USCF members along with millions of others - bought one or another of the early machines, and ultimately lost interest because the level of play just was not challenging enough.

Because the USCF rating system is the most widely recognized measure of chess skill, the performance of chess microcomputers tends to be described as a USCF rating. Sometimes real USCF ratings were obtained for the computers, by playing them in one or two tournaments. Too often, though, there has not been a solid basis for the claims made for the machines. Even when the manufacturer made a good-faith effort to get a real rating, the results were frequently misleading - provisional ratings based on a few games just are not very accurate. Also, the prototype units entered in tournaments have been known to play much more strongly than the eventual production models. 